\title{
Quantitative approaches to productivity and borrowing in Maltese derivation
}

\author{
Benjamin Saade ${ }^{1}$
}

Received: 19 June 2018 / Accepted: 30 May 2020 / Published online: 22 June 2020

(C) The Author(s) 2020

\begin{abstract}
This paper applies quantitative measures of productivity to a selection of Maltese derivational affixes borrowed from Italian/Sicilian. The productivity rankings of the selected affixes are compared to their Italian sources revealing identical rankings for the most productive affixes and slightly deviating rankings for the less productive affixes. It is argued that morphological productivity scores and the subsequent rankings form a pattern that is established in the recipient language by the sum of matter borrowings of formations involving the respective affixes. In conjunction with a discussion of the mixed lexicon and morphology of Maltese, a case is made that converging or diverging productivity rankings can be explained by wellstudied variables in language contact studies: intensity of contact, availability of registers/repertoires, and route of borrowing (direct/indirect). In addition it is shown that the cross-linguistic application of other quantitative measures, including a newly proposed Integration Factor and Seifart's criteria for direct and indirect borrowing, can help uncover where the distributions of donor and recipient language affixes diverge, providing an exploratory tool for morphologist and contact linguists alike.
\end{abstract}

Keywords Borrowing $\cdot$ Productivity $\cdot$ Derivation $\cdot$ Maltese $\cdot$ Italian

\section{Introduction}

The quantitative study of morphological productivity is almost exclusively applied to single languages. In particular English, German and the major Romance languages make up the bulk of applications of the method. In these single language studies productivity is investigated synchronically as well as diachronically. While there have

B. Saade

bsaade@uni-bremen.de

1 Malta Centre, Department of Linguistics and Literary Studies, University of Bremen,

P.O. Box 330440, 28334 Bremen, Germany 
been a few studies trying to apply the method in a comparative fashion across languages, their employed methodology is not without flaws and they have a very restricted focus. A study by Gatt and Fabri (2018) assesses the productivity of two Italian affixes borrowed into Maltese but does not venture into a comparison with the productivity of the original source suffixes in Italian. Other studies (Saade 2016, 2019) have advanced the comparative methodology with a more appropriate approach but did not show in detail what the contribution of these studies to the theory of language contact might be. In this paper, the role of productivity as a bird's eye view on morphological borrowing is discussed in a case-study on borrowed Italian/Sicilian derivation in Maltese. As a lexically mixed language (Arabic/Sicilian/Italian/English), Maltese is a perfect test case for the viability of the proposed procedure. The employed methodology is proposed as an exploratory diagnostic for different phenomena of language contact, touching on issues of MAT vs. PAT borrowing (Sakel 2007), loanword integration (Gardani 2020:98-103), and neologism formation. In addition, Seifart's (2015) criteria for direct vs indirect borrowing are applied to the sample of affixes to explore possible borrowing routes. Finally, the results of these investigations are integrated into current theories of language contact (Matras 2009; Thomason 2001) and show how these quantitative measures can shed light on different borrowing scenarios. Section 2 gives a brief summary of the contact history and the present multilingual setting in Malta. Section 3 provides an overview of the mixed lexicon of Maltese, while Sect. 4 discusses the degree to which the morphology of Maltese is mixed, additionally summarizing the forms and functions of borrowed Italian derivation found in present-day Maltese. In Sect. 5, three types of calculations are applied to a subset of borrowed Italian derivational affixes: a modified Baayen's P, measures proposed by Seifart (2015) to distinguish between direct and indirect borrowing, and the Integration Factor, to be introduced in this paper. This triangulation of methods can help us to understand the borrowing history of Maltese in more detail. This hypothesis is fleshed out and generalized in Sect. 6 where a correlation between the productivity rankings of borrowed morphology and different language contact situations is proposed. Section 7 ties the results of the studies together and gives some concluding thoughts.

\section{The multilingual past and present of Maltese}

Maltese is a descendant of Siculo Arabic, a pre-Hilalian variety of Arabic spoken in Sicily to various degrees from the 7th century until the 13th century (Agius 2012). Although Punic and Byzantine contact with the Maltese islands is attested before the colonization of Malta by Arabs from Sicily first in 870 and then in 1048, there is no evidence of a transmission of language in these cases (Brincat 2011:32). Latin is considered to have been spoken on the Maltese islands at some point between 218 $\mathrm{BC}$ and AD 476 but a substratum effect on present day Maltese is only detectable in some toponyms (Brincat 2011:19-24). Contact with Sicilian gradually started with the Norman conquest of Sicily between 1025 and 1090 and was continuous until 1900 (Brincat 2011:xxxvi). However, with the arrival of the Knights of St. John in 1530 (Tuscan) Italian spread first to administration and later also gradually became 
the language of culture in Malta while diminishing the influence of Sicilian. The dominance of Italian even continued after the British rule of Malta began in 1800 . The influence of English grew stronger and has continued until the present day while Italian lost some of its clout although it experienced a brief renaissance due to the reception of Italian television programs starting in 1957 (Brincat 2011:xxxvi-xxxix). All these influences have left their mark on the original variety of Arabic spoken on Sicily and formed the Maltese language. ${ }^{1}$ Also today, the Maltese islands are a multilingual landscape. Even after the independence of Malta from Britain, the population is still bilingual Maltese-English. Codeswitching is commonplace, public and private signage is heavily mixed and/or bilingual. There is a continuum of Maltese speakers ranging from almost exclusively Maltese-speaking to almost exclusively English-speaking, while more and more descriptions of Maltese English as a variety in its own right have emerged in the last years (among others Bonnici 2009; Bonnici et al. 2012). All these factors (both synchronic and diachronic) have an impact on the lexicon and grammar of Maltese. These influences will be discussed in Sect. 3 and Sect. 4.

\section{Mixed lexicon of Maltese}

Due to its long and varied contact history and multilingual present, Maltese serves as an excellent laboratory for studies on language contact, as shown by different quantitative works on the composition of the Maltese lexicon (e.g. Cohen 1965; Fenech 1978). A study by Brincat (2011) uses the most comprehensive MalteseEnglish dictionary by Aquilina as an empirical basis. The study is entirely typebased and also shows the inherent biases of other dictionary studies: many archaic items are included, and since the dictionary is designed for the best possible coverage, much technical and specialist vocabulary is counted in. With this methodology, the Arabic lexical component is estimated at a mere $32.41 \%$ while Italian/Sicilian items make up $52.46 \%$ of the lexicon. ${ }^{2}$ A more recent study by Comrie and Spagnol (2016) uses the methodological grid of the Loanwords in the World's languages project (Haspelmath and Tadmor 2009) which takes a list of 1500 items from different semantic fields as its basis. Here, the picture changes in comparison with the dictionary study towards a larger Arabic lexical component $(56 \%)$ and a smaller Sicilian/Italian component (30.3\%). A third study by Stolz (2003) takes the extended Swadesh 207-item list as an even more restricted basis. Here the proportion of Italian/Sicilian loanwords is still lower than in the other two studies $(27.58 \%)$. A reassessment of the 200 -word Swadesh list for Maltese without taking

\footnotetext{
${ }^{1}$ In the remainder of this article, the terms Italian and Italian/Sicilian are used interchangeably (both denoting Tuscan, Italian or Sicilian origin) unless otherwise stated since the ultimate source of lexical and morphological material is almost impossible to decide in most cases. See also Comrie and Spagnol (2016) for further discussion of this classification problem. Furthermore the terms Arabic and Arabic Maltese are used interchangeably denoting the inherited Siculo-Arabic component of lexicon and grammar in present day Maltese.

${ }^{2}$ Bovingdon and Dalli (2006) come to a similar result with a randomly generated 1000-item word list albeit with a slightly higher proportion of Arabic etyma (54\% Italian, 41\% Arabic, 4\% English, 1\% other).
} 
Table 1 Comparison of quantitative studies on the composition of the Maltese lexicon

\begin{tabular}{lllll}
\hline Origin & $\begin{array}{l}\text { \% of lexicon in } \\
\text { dictionary study } \\
\text { (Brincat 2011) }\end{array}$ & $\begin{array}{l}\text { \% of lexicon in } \\
1,500 \text { item word list } \\
\text { (Comrie and } \\
\text { Spagnol 2016) }\end{array}$ & $\begin{array}{l}\text { \% of lexicon in } \\
\text { 200-word Swadesh } \\
\text { list with synonyms } \\
\text { (Stolz 2003) }\end{array}$ & $\begin{array}{l}\text { \% of lexicon in } \\
\text { list without synonyms } \\
\text { (personal count) }\end{array}$ \\
\hline Arabic/Semitic & 32.41 & 56 & 72.42 & 92 \\
Italian/Sicilian & 52.46 & 30.3 & 27.58 & 8 \\
English & 6.21 & 4.8 & - & - \\
Other & 8.2 & 8.9 & - & - \\
\hline
\end{tabular}

synonyms into account shows that the Romance component shrinks to a mere $8 \%$ (Table 1).

A closer look at the loanwords by semantic field in Comrie and Spagnol (2016:326-327) reveals a familiar cross-linguistic tendency: concepts pertaining to the modern world, technology, law are among the areas with the most loanwords, while more basic semantic fields such as quantity and body parts have the lowest proportion of loanwords. The only category that behaves against the world-wide trend is kinship terms $(27.5 \%$ borrowed) which has a comparatively higher proportion of loans compared to the world average of $15 \%$. Looking at the loanwords by word class also reveals a wide-spread tendency in borrowing: loans are most frequent with adjectives and nouns and less frequent with verbs and function words (Comrie and Spagnol 2016:327-328).

The different results of studies on the composition of the Maltese lexicon ranging from dictionary to medium-sized word list to core vocabulary show that the Italian/Sicilian component of the Maltese has not permeated the core vocabulary as much as it has special terminology and concepts of the modern world. This is one of the reasons that Maltese is not counted among true Mixed Languages in the sense of Bakker and Mous (1994) and deemed "not quite the right mixture" by Stolz (2003). Another reason for the exclusion from the list of Mixed Languages is the lack of intertwining in morphology. The extent to which Maltese still possesses a mixed morphology in addition to a mixed lexicon will be discussed in the next section.

\section{Mixed morphology of Maltese}

The contact history and multilingual present of Malta also affects the morphological system of Maltese to various degrees. Although Arabic root-and-pattern morphology still covers the majority of the morphological functions, more and more Italian and (in more subtle ways) English morphology starts to gain ground. Since Aquilina's (1958) notable work on the mixed nature of Maltese grammar, numerous studies have focused on different subtopics, such as the integration of loan verbs and the mixed verbal morphology of Maltese (Mifsud 1995; Spagnol 2011), the question whether Maltese can be classified as mixed language (Drewes 1994; Stolz 2003; Versteegh 2017), and syntactic phenomena influenced by language contact (among others: Vanhove 1994, 2001). The most relevant study on Italian-origin morphology 
Table 2 Mixed inflectional morphology in Maltese

Table 3 Mixed derivational morphology in Maltese

\begin{tabular}{lcccc|} 
& & \multicolumn{3}{c}{ Inflectional morphology } \\
& & Arabic & Italian & English \\
\cline { 3 - 5 } & Arabic & Y & N & N \\
Lexical & Italian & Y & Y & N \\
bases & English & Y & Y & Y \\
\cline { 3 - 5 } & & & &
\end{tabular}

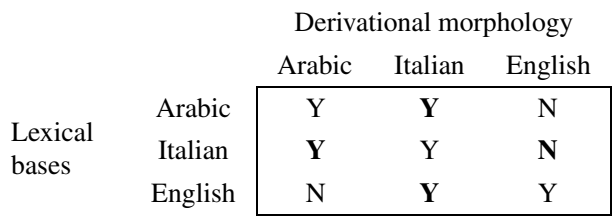

in Maltese is Tosco (1993), who gives a good overview of Italian-borrowed formatives in Maltese and briefly discusses their applicability to Maltese Arabic bases. While most of the phenomena described in this section are at least partly described, a systematic overview of mixed morphological formations in Maltese is sorely missing.

As we are dealing with three etymological strata in Maltese (Arabic Maltese, Italian, English) a cross-section involving both morphology (potentially coming from each stratum) and lexical bases (potentially coming from each stratum) provides the most useful overview of the spread of the different morphological systems and their application. Instead of giving a single cross-section, the results are split up into inflectional and derivational morphology allowing for more fine-grained observations. The following Tables 2 and 3 summarize which combinations of bases and morphology can be observed in Maltese ( $\mathrm{Y}$ stands for 'combination of morphology and lexical base attested', while $\mathrm{N}$ stands for 'combination of morphology and lexical base not attested'). Table 2 shows that Arabic inflectional morphology applies to all etymological strata present in Maltese (Arabic, Italian, English), while Italian inflectional morphology can only apply to Italian and English bases. English inflectional morphology can only apply to English bases.

For derivational morphology the picture changes in two respects (corresponding to two cells in the Table 3). In contrast to inflection, Arabic derivational morphology is not applied to English bases, while Italian derivation can additionally be applied to Arabic bases (unlike Italian inflectional morphology).

Tables 2-3 only indicate whether the application of formatives to a base with a certain source is possible. The token frequency of these combinations is another matter, which will be discussed for Italian morphology in Sect. 5.2. The usual or unsurprising combinations of base and morphology from the same stratum (Arabic + Arabic, Italian + Italian, English + English) will not be illustrated further (for explanations why this type of combination is not relevant for morphological borrowing, see Gardani 2008, 2012, 2018, 2020; Gardani et al. 2015). In the following, the combinations of base and morphology from different strata in Maltese will be explained along with examples for each case. An example of Arabic morphology operating on Italian bases in inflection is plural formation. The borrowed Italian lexeme pjazza is pluralized with an Arabic non-concatenative broken plural template yielding pjazez as illustrated in (1). 
(1) Inflection - Italian base + Arabic morphology [MLRS, ${ }^{3}$ news148409]

In-nies ${ }^{4}$ fit-triq $u$ fil-pjazez kollha fehm-u

DEF-people in:DEF-street and in:DEF-squares all understand:IPFV-3.PL

$x$ ried j-ghid Joseph.

what want:3SG.M.PFV 3SG.M-say:IPFV Joseph

'The people in the street and in the squares all understood what Joseph wanted to say.'

A similar example can be found in (2), this time exemplifying how Arabic inflectional morphology is applied to English bases. Here too, a broken plural strategy is used to pluralize the borrowed English lexeme kettle.

(2) Inflection - English base + Arabic morphology [MLRS, parl8178]

[...] nитru oћra ta' ktieli j-in-sab-u mi-żmum-a

number other of kettle:PL 3M-PASS-find:IPFV-PL PTCP.PST-hold-F

fl-istore $[\ldots]$

in:DEF-store

'another number of kettles are found (held) in the store'

The examples in (3) and (4) shows how the Italian-origin past participle marker $\{-u t\}$ (cf. Italian -uto, e.g. in bevuto 'drunk') attaches to the English verbal base spell. One could argue that in (3) the resulting participle is used adjectivally and not verbally and thus crossing over into derivation. However, both uses of the participle (verbal and adjectival) are attested equally in Maltese, with a verbal use exemplified in (4).

Inflection - English base + Italian morphology [MLRS, news86173]

L-SMS holoq vokabolarju gdid, kliem gdid

DEF-sms create:PFV:3SG.M vocabulary new word:COLL new

spell-ut differenti

spell-PTCP.PST different

'The SMS created a new vocabulary, new words spelled differently.'

(4) Inflection - English base + Italian morphology (strictly verbal use) [MLRS, news86173]

\section{[...]il-ћin j-ista' j-kun spell-ut numru}

DEF-time 3SG.M-can:IPFV 3SG.M.IPFV-be spell-PTCP.PST number

numru [...]

number

'The time can be spelled/written number by number.'

\footnotetext{
${ }^{3}$ Maltese Language Resource Server corpus, available at http://mlrs.research.um.edu.mt/CQPweb/malti03/. The corpus is described in Gatt and Čéplö (2013). Unless otherwise stated, all corpus data come from the press section of the MLRS version 3.0 (approximately 89 million tokens).

${ }^{4}$ The Maltese definite article $\{i l-\}$ in all its assimilated forms and combinations with prepositions is separated with a hyphen in standard Maltese orthography. All other hyphens in the language examples represent non-orthographic morpheme breaks.
} 
As far as derivational morphology is concerned, example (5) shows that the borrowed Italian base noun pipa 'pipe' is verbalized with Arabic root-and-pattern morphology using the root consonants $\sqrt{P J P}$, yielding pejjep 'to smoke' by gemination of the second root consonant. Another example of this type of formation is the verb fannad 'to dig deep' from Italian fondo 'deep' (Brincat and Mifsud 2015:3355).

$$
\begin{aligned}
& \text { Derivation - Italian base + Arabic morphology [MLRS, literature2] } \\
& \text { Il-cameraman kien qed i-pejjep iehor [...] } \\
& \text { DEF-cameraman be:3SG.M.PFV PROG 3SG.M-smoke:IPFV another } \\
& \text { 'The cameraman was smoking another one [...]' }
\end{aligned}
$$

Example (6) shows that the borrowed Italian agentive/instrumental nominalizer \{tur\} (cf. Sicilian -turi, Italian -tore, e.g. in lavoratore 'worker') applies to the borrowed English verbal base ićcekkja 'to check', resulting in the formation cekkjatur 'checker'.

(6) Derivation - English base + Italian morphology [MLRS, news68540]

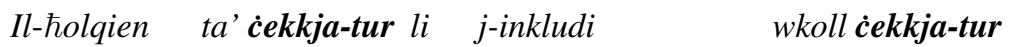
DEF-creation of check-AGT SUB 3SG.M-include:IPFV also check-AGT tal-grammatika hu bićca xoghol ikkumplikata $u$ estensiva of:DEF-grammar 3SG.M piece(F) work complicated:F and extensive:F 'The creation of a checker that also includes a grammar checker is a complicated and extensive piece of work.'

Finally, the type of word formation in (7) exemplifies the possibility of applying borrowed Italian derivation also to Arabic bases in Maltese. In this case the borrowed Italian nominalizer $\{$-tura $\}$ derives the deverbal noun faqqatura 'a crack' from the Maltese Arabic base faqqa' 'to crack'.

$$
\text { Derivation - Arabic base + Italian morphology [MLRS, news118897] }
$$

[...] l-istazzjon ji-nt-laqat minn sajjetta u n-isma'

DEF-station 3M-PASS-hit:IPFV from lightning and 1SG-hear:IPFV

faqqa-tura bћal splużjoni kbira fil-vicin.

crack-NMLZ like explosion big:F in:DEF-proximity

'the station was being hit by lightning and I heard a crack like a big explosion nearby.'

In addition, in Maltese there are cases that do not easily fit into this proposed typology of mixed formations. Brincat and Mifsud (2015:3363-3365) address the subtle influence of English on formations that are superficially Italian/Sicilian. Formations such as awditur 'auditor' and evalwazzjoni 'evaluation' do not have equivalents in Italian (the Italian terms for the Maltese meanings would be revisore dei conti and valutazione, respectively). The semantics come from English auditor and evaluation, while the form is ultimately of Romance origin. In such instances it is not trivial to decide whether the formations instantiate a real application of the formatives $\{$-tur $\}$ and $\{-z z j o n i\}$ or represent direct loans from English which are integrated into Maltese 
Table 4 Selection of Italian derivational affixes in Maltese

\begin{tabular}{|c|c|c|}
\hline Affix & Function & Example \\
\hline$-a z z$ & pejorative & pupa 'doll' > pupazz 'puppet' \\
\hline$-u n$ & augmentative & berritta 'cap' > berrittun 'large cap' \\
\hline$-o t t$ & augmentative & guvni 'teen' > ġuvnott 'young man' \\
\hline -in & diminutive & biskott 'biscuit' > biskuttina 'small biscuit' \\
\hline -etta & diminutive & tromba 'cylindrical shape' > trumbetta 'trumpet' \\
\hline$-a r$ & deverbal noun & arlog் 'watch' > arlug ġar 'watch mender' \\
\hline -tur & agent & 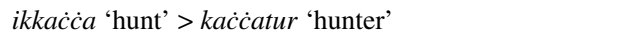 \\
\hline$-i \ddot{c} i$ & female agent & attur 'actor' > attrici 'actress' \\
\hline$-a t a$ & singulative & ippassigga 'to walk' > passiggata 'a walk' \\
\hline -tura & deverbal noun (often singulative) & spara 'to shoot' > sparatura 'a shot' \\
\hline$-n z a$ & deverbal noun & spera 'to hope' > speranza 'hope' \\
\hline -zzjoni & deverbal noun & organizza 'to organize' > organizzazzjoni 'organization' \\
\hline$-a \dot{g} \dot{g}$ & deverbal noun & arbitra 'to arbitrate' > arbitrag $\dot{g}$ 'arbitration' \\
\hline$-e z z a$ & deadjectival noun & $\dot{c} e r t$ 'certain' > certezza 'certainty' \\
\hline$-i(e) t a ̀$ & deadjectival noun & leal 'loyal' > lealta 'loyalty' \\
\hline$-i z m u$ & deadjectival noun & senswuali 'sensual' > senswualizmu 'sensualism' \\
\hline$s-/ \dot{z}-$ & negative & kwalifikat 'qualified' > skwalifikat 'disqualified' \\
\hline dis-/diż- & negative & onest 'honest' > diżonest 'dishonest' \\
\hline -ment & adverbializer & serju 'serious' -> serjament 'seriously' \\
\hline
\end{tabular}

using an Italian form. ${ }^{5}$ Having established a general typology of hybrid formations in Maltese, Sect. 4.1 gives an overview of the forms and functions of borrowed Italian derivational affixes which, as was shown here, can apply to bases of all main etymological strata in Maltese, namely Arabic, English, and Italian.

\subsection{Borrowed Italian/Sicilian derivation in Maltese}

At first glance, Italian derivation is pervasive in Maltese in terms of both types and tokens. Grammatical descriptions such as Borg and Azzopardi-Alexander (1997:190191;278-297) give long lists of Italian derivational formatives with a host of different functions. Table 4 provides an (abridged) overview of the formatives.

The Italian-origin formatives cover many different functions and also operate on all major word classes in Maltese. Aside from some minor remark Borg and Azzopardi-Alexander (1997:278) do not comment on the productivity of these formatives or the spread to native Maltese Arabic bases. A first superficial look reveals that an overwhelming majority of types and tokens of Italian derivational morphology is only present with Italian bases. In theory, all of the formations could be classified as loanwords borrowed in toto into Maltese since they have a clear source in Italian

\footnotetext{
${ }^{5}$ Although formations such as awditur 'auditor' do not fit into the exact typology here, they will be nonetheless included in the quantitative analysis in Sects. 5.1 and 5.2 since they still represent instances of the respective affix.
} 
Table 5 Italian affixes in Maltese participating in hybrid formations

\begin{tabular}{|c|c|c|}
\hline Affix & Base & Example \\
\hline$-a r$ & English & iddajvja 'to dive' > iddajvjar 'diving' (Drewes 1994:92) \\
\hline$-u t /-a t$ & English & inxurja 'to insure' > inxurjat 'insured' (Drewes 1994:92) \\
\hline -tura & English & ikkraxxja 'to crash' > kraxxjatura 'crash' (Drewes 1994:93) \\
\hline$-a t a$ & Arabic Maltese & xemx 'sun' > xemxata 'sunstroke' (Drewes 1994:93) \\
\hline -tur & English & ixxiftja 'to shift' > xiftjatur 'shift worker' (Drewes 1994:93) \\
\hline$-u \dot{z}$ & Arabic Maltese & nkejja ‘vexation' > nkejjuż ‘annoying' (Drewes 1994:93) \\
\hline$-a z z$ & Arabic Maltese & sakran 'drunk' > sakranazz ‘drunkard' (Drewes 1994:94) \\
\hline- un & Arabic Maltese & dar 'house' > darun 'large house' (Brincat and Mifsud 2015:3350) \\
\hline$-i z m u$ & Arabic Maltese & 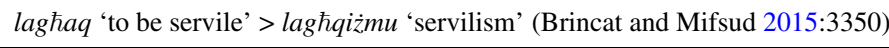 \\
\hline
\end{tabular}

(except sparatura). However, Drewes (1994) and Brincat and Mifsud (2015) identify a number of Italian/Sicilian affixes that do attach to Arabic Maltese and English bases (Table 5).

Since these lists are mostly constructed via intuition and/or elicitation, a solid quantitative approach to the phenomenon is necessary to investigate productivity, usage frequencies and loan-suffix integration into the Maltese grammatical system. In the next section, the productivity of borrowed Italian affixes in Maltese will be measured by means of three quantitative approaches.

\section{Quantitative approaches to the productivity of borrowed derivation in Maltese}

In Sect. 5.1, a quantitative measure of morphological productivity, Baayen's $P$ (Baayen 2009), is used comparatively for a subset of borrowed Italian derivational affixes in Maltese. The viability of the results and their meaningfulness for language contact studies are discussed with respect to the notions of hapax legomena and hybrid formation. In Sect. 5.2, I will propose a new measure for gauging the integration of borrowed affixes, the Integration Factor. In addition, further quantitative measures regarding borrowing scenarios of affixes, Seifart's (2015) criteria for direct vs. indirect borrowing, are applied to a subset of the data, in Sect. 5.3.

\subsection{Comparing productivity between Maltese and Italian}

Although productivity is often employed as a technical term in studies concerning morphological borrowing to indicate integration and pervasiveness of certain formatives, the available and tested quantitative methods of assessing productivity are rarely used in the field of language contact studies. Some investigations have used quantitative methods, but they either have a different focus or suffer from major methodological flaws. An example of the former is Papoutsis (2014), who compares the productivity of two not cognate borrowed affixes, the functional equivalents English $\{-n e s s\}$ and Greek $\{-t i t a\}$; an example of the latter is Majtényi (2012), who does not 
Table 6 Baayen's $P$ and productivity rank for seven derivational affixes compared between Maltese and Italian

\begin{tabular}{lllll}
\hline & \multicolumn{2}{c}{$P * 10^{3}(N=19 \mathrm{k})$} & \multicolumn{2}{l}{ Rank $(N=19 \mathrm{k})$} \\
Affix & Maltese & Italian & Maltese & Italian \\
\hline -zzjoni /-zione & 7.63 & 13.4 & 1 & 1 \\
- i(e)tà & 4.96 & 13.4 & 2 & 2 \\
-bbli /-bile & 2.84 & 11.3 & 3 & 3 \\
-tur /-tore & 2.8 & 9.4 & 4 & 4 \\
-nza & 1.76 & 0.7 & 5 & 7 \\
-tura & 1.69 & 6.6 & 6 & 5 \\
-ag் / -aggio & 0.66 & 1.5 & 7 & 6 \\
\hline
\end{tabular}

control for different corpus sizes in her study on the productivity of borrowed German über - in English and Hungarian. In a previous study, Saade (2019) compared the productivity of a selection of five cognate affixes in Maltese and Italian using Baayen's $P$ (potential productivity) (Baayen 2009) combined with the variable corpus approach proposed by Gaeta and Ricca (2006). ${ }^{6}$ Baayen's $P$ is a measure that treats hapax legomena (a type/formation with an affix that appears only once in a corpus) as indicative of productivity when related to the total number of tokens of the affix $\left(N_{\max }\right)$ in the same corpus (formula $P=h / N_{\max }$ ). The variable corpus approach by Gaeta and Ricca (2006) allows the comparison of productivity of affixes with vastly different token sizes without an inherent statistical bias of Baayen's $P$ which overestimates the productivity of very infrequent affixes and underestimates the productivity of very frequent affixes. Gaeta and Ricca (2006) calculate Baayen's $P$ for a selection of deverbal and deadjectival derivational affixes in Italian. For a subset of this selection, this method was replicated for the corresponding borrowed affixes in Maltese using interpolation with ZipfR (Evert and Baroni 2007). The values for Italian are taken from Gaeta and Ricca (2006:69).

Table 6 shows the results of Saade (2019) adding the two high-frequency suffixes $\{-z z j o n i\}$ and $\{-i(e) t \grave{a}\}$ to the comparison while additionally giving the productivity ranks of the suffixes in Maltese and Italian. The ranks are quite constant overall, except for the lower region where the ranking of affixes deviates. One of the deviating affixes $\{-n z a\}$ represents the only instance of a borrowed affix in Maltese with a higher productivity score than its Italian cognate. Before discussing what the relative uniformity of productivity ranks might tell us about language contact scenarios in Sect. 6, the following subsections provide additional measures relating to productivity and integration of the borrowed affixes in Maltese while first critically discussing productivity as a valid measure of integration.

\subsection{Hybrid formations vs hapaxes: towards the Integration Factor (IF)}

While Baayen's $P$ gives a reliable measure of productivity for inherited affixes, it is not clear whether the measure is as informative for studies on borrowed morphology

\footnotetext{
${ }^{6}$ More details of the method (and its limitations) can be found in Saade (2019) and Gaeta and Ricca (2006). Here, only the most important facets of the method are given.
} 
Table 7 Hybrid formations with Italian borrowed affixes in Maltese (corpus study)

\begin{tabular}{|c|c|c|c|}
\hline Type & Meaning & Base & Tokens \\
\hline sibbina $\dot{g} \dot{g}$ & plundering & Arabic siba 'plunder' & 1 \\
\hline xabbatur & climber & Arabic $x a b b$ 'to climb' & 25 \\
\hline 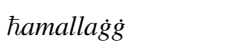 & low class behavior & Arabic ћamallu 'vulgar' & 5 \\
\hline cekkjatur & checker & English ićcekkja 'check' & 4 \\
\hline affordabbli & affordable & English affordja 'afford' & 137 \\
\hline gammjatura & jamming & English iggammja 'to jam' & 1 \\
\hline faqqatura & crack & Arabic faqa' 'to burst' & 4 \\
\hline xabbatura & climbing & Arabic $x a b b$ 'to climb' & 3 \\
\hline twistjatura & type & English ittwistja 'twist' & 2 \\
\hline klikkjatura & a click & English ikklikkja 'to click' & 1 \\
\hline weldjatura & welding & English iwweldja 'to weld' & 1 \\
\hline praspura & oddity & Arabic paspar 'to do silly things' & 79 \\
\hline puxxjatura & push & English ippuxxja 'to push' & 9 \\
\hline pedestrijanizzazzjoni & pedestrianization & English ippedestrijanizza 'to pedestrianize' & 1 \\
\hline xarabankizzazzjoni & xarabankization $^{8}$ & proper name & 1 \\
\hline Peppinizzazzjoni & Peppinization ${ }^{9}$ & proper name & 1 \\
\hline rigezzjoni & rejection & English irrigetta 'to reject' & 3 \\
\hline deterjorazzjoni & deterioration & English iddeterjora 'to deteriorate' & 108 \\
\hline
\end{tabular}

in languages with a heavily mixed lexicon such as Maltese. Part of the problem lies in the fact that while hapax legomena are a good indicator of productivity, their value as an indicator of integration is doubtful, since not all neologisms are important for integration in the same way (clearly, hybrid formations or even hybrid neologisms are stronger indicators of integration than new formations with Italian bases). Using hapax-based measures is "an indirect way of estimating the rate at which a morphological category enriches the vocabulary" since neologisms (as a measure of lexical enrichment) "are found primarily among the hapax legomena" (Baayen 2009:905). The number of hybrid formations with a borrowed affix should provide information on the integration of affixes in a much more direct way. However, hybrid formations do not necessarily have to be hapax legomena, and even more importantly, unlike neologisms they do not even cluster dominantly in the class of hapax legomena in Maltese (see Table 7). In a manual analysis of the type lists of the seven studied affixes the following hybrid formations and their token counts were found in Maltese. ${ }^{7}$

Hybrid formations with Italian derivational morphology in Maltese are found with vastly different token counts. Although seven out of 19 formations occur only once and thus count as hapax legomena, the majority of the formations display higher frequency. Interestingly, some affixes show preferences for certain non-Italian etymological strata: $\{-a \dot{g} \dot{g}\}$ only applies to Arabic Maltese bases, while $\{-b b l i\}$ and

\footnotetext{
${ }^{7}$ This study also uses the press section of the MLRS corpus version 3.0.

${ }^{8}$ Xarabank is a popular talk show on Maltese television.

${ }^{9}$ Peppi Azzopardi is the host of Xarabank.
} 
Table 8 Integration Factor (IF) for 7 Italian-origin derivational affixes in Maltese

\begin{tabular}{lllll}
\hline Affix $\quad$ HF(types $)$ & $N_{\max }$ & IF $* 10^{3}$ & IF rank & $\begin{array}{l}\text { Productivity } \\
\operatorname{rank}(N=19 \mathrm{k})\end{array}$ \\
& & &
\end{tabular}

\begin{tabular}{llllll}
-tura & 8 & 73775 & 0.1 & 1 & 6 \\
-zzjoni & 5 & 939666 & 0.005 & 5 & 1 \\
-agg & 2 & 56505 & 0.035 & 2 & 7 \\
-tur & 2 & 134807 & 0.015 & 3 & 4 \\
-bbli & 1 & 74453 & 0.013 & 4 & 3 \\
-nza & 0 & 233526 & 0 & 6 & 5 \\
-i(e)tà & 0 & 239913 & 0 & 6 & 2 \\
\hline
\end{tabular}

$\{-z z$ joni $\}$ apply only to English bases (with the exception of proper names). The affixes $\{$-tur $\}$ and $\{$-tura $\}$ are most variable and apply to English as well as Arabic Maltese bases. For two affixes, $\{-n z a\}$ and $\{-i(e) t \grave{a}\}$, no hybrid formation was found in the corpus.

In order to give a quantitative estimation of the applicability of the affixes to nonItalian bases, the integration factor (IF) as a more fitting measure is proposed here as an alternative to Baayen's $P$. Unlike Baayen's $P$, the IF takes the number (types) of hybrid formations (HF) as a numerator: $\mathrm{IF}=\mathrm{HF} / N_{\max }$. This can be read as: hybrid formations per token of an affix in a corpus.

The comparison of the rankings according to IF and productivity in Table 8 shows that IF and productivity are not correlated (Spearman's Rho rank correlation $=-0.63$, $p$ not significant at $=0.12889)$ suggesting that different facets of the distribution of affixes are described with each criterion. According to the measure, $\{$-tura $\}$ is the most integrated affix which corresponds fittingly with its ability to attach to English as well as Maltese Arabic bases. The affix $\{-a \dot{g} \dot{g}\}$ achieves the second highest IF although it only applies to Arabic Maltese bases, followed by $\{-t u r\}$ in third place, which can also apply to Arabic and English bases. Although further corroborating applications of this method are needed, for other borrowed affixes in Maltese as well as in further investigations on other language pairs, the IF is a more promising measure of integration than Baayen's $P$ for it puts the hybridity of formations into focus. In the next subsection, a third quantitative measure, developed in Seifart (2015), is applied to the Maltese case.

\subsection{Direct vs indirect borrowing of Italian derivation in Maltese}

In order to obtain a more complete picture of the borrowing situation, three quantitative measures proposed by Seifart (2015) are applied to the Maltese case, more specifically to the three suffixes $\{-n z a\},\{-t u r a\}$ and $\{-a \dot{g} \dot{g}\}$, for which a discrepancy in rank compared to the Italian suffixes was detected in Sect. 5.1.

Building on previous proposals, Seifart (2015) proposes to differentiate between two different routes of affix borrowing: on the one hand, affixes that were borrowed directly without (or just with limited) knowledge of the source language: direct borrowing; on the other hand, affixes that were borrowed after a significant number of complex loanwords were already present in the recipient language and the knowledge of the source language is quite extensive: indirect borrowing. He proposes three 
quantitative criteria that help to distinguish between these two different borrowing processes.

\section{Ratio of complex loanwords to hybrid formations ${ }^{10}$}

The rationale behind this measure is the following: the higher the proportion of complex loanwords is for an affix compared to hybrid formations in a language, the more probable it is that indirect borrowing occurred: the affix most likely spread from borrowed complex loanwords that were already present in the recipient language. In the case of a low proportion of complex loanwords (or, conversely, a majority of hybrid formations), the direct affix borrowing route is deemed more parsimonious (Seifart 2015:513-514).

\section{Complex loanwords paired with a simplex loanword}

This criterion assumes that the presence of simplex loanword bases (e.g. profit, honor) in addition to complex loanwords (profitable, honorable) "makes an affix even more salient [...], as these pairs allow speakers to directly experience the segmentability and the meaning contribution of the affix" (Seifart 2015:514).

\section{Complex loanwords infrequent relative to their simplex loanword}

This criterion is largely based on works on productivity by Hay (2001) and Baayen (2009), who argue that the relative frequency between a morphological base and its derived form has consequences for language processing and in turn on the productivity of affixes. If many formations with an affix are more frequent than the respective base, it is argued that the complex derived form will not likely be (de-)constructed online but instead produced/processed as a whole. Since this processing route activates only the whole formation and not the affix itself, the activation of the suffix (and therefore its potential productivity) is lower than in cases where complex formations containing an affix have a lower frequency than the base itself.

A criticism of the last two criteria might be that they are not independent enough. Complex formations that do not have a simplex loanword are automatically more frequent than their bases (as there are none). Further investigations have to show whether these two criteria really measure different things that are relevant to the two affix borrowing scenarios. As an alternative, they could either be combined or one of the measures could be discarded. Moreover, it is unclear to what kind of base forms the calculations for criterion 3 apply: in the case of heavily inflecting languages, should all inflected forms be included in the count? If a borrowed affix applies to adjectives in the source language but the recipient language only borrowed verbal and nominal forms of a given lexeme (plus the complex loanwords), should they be included in the count or discarded? In the case of Italian $\{$-tura $\}$ there is additional uncertainty about

\footnotetext{
${ }^{10}$ The first criterion is slightly confusingly named: what is presented by Seifart is the ratio of complex loanwords and the total number (types) of all formations (hybrid formations and complex loanwords combined) with the respective affix in a language.
} 
Table 9 Seifart's measures applied to three Italian-origin affixes in Maltese

\begin{tabular}{llll}
\hline Affix & $\begin{array}{l}\text { Ratio of complex } \\
\text { loanwords to hybrid } \\
\text { formations }\end{array}$ & $\begin{array}{l}\text { Complex loanwords } \\
\text { paired with a simplex } \\
\text { loanword }\end{array}$ & $\begin{array}{l}\text { Complex loanwords } \\
\text { infrequent relative to } \\
\text { their simplex loanword }\end{array}$ \\
\hline$-n z a$ & $1(285 / 285)$ & $0.30(87 / 285)$ & $0.17(50 / 285)$ \\
-tura & $0.95(161 / 169)$ & $0.37(60 / 161)$ & $0.24(38 / 161)$ \\
$-a \dot{g} \dot{g}$ & $0.97(82 / 84)$ & $0.20(17 / 82)$ & $0.06(5 / 82)$ \\
\hline
\end{tabular}

the exact base even in the source language. Gaeta (2004:335) discusses two possibilities for $\{$-tura $\}$ (past participle vs verbal theme as base the for derivation). Again, Seifart (2015) does not make clear which base should be included in the count. Additionally, there might be changes in language contact regarding which base is used by speakers for derivation if more than one derivation route is possible. Another criticism concerns the notion hybrid formation as far as Seifart's first criterion and its application in the study of morphological borrowing are concerned. Many definitions of this term take recourse to the notion of native base. In the case of Maltese (and in many other contact situations as well), this is problematic. As we have seen in Sect. 4 and Sect. 5.2, many neologisms in Maltese are formed with Italian derivational affixes attaching to English bases, both from the Latinate and the Germanic stratum of the English lexicon (puxxjatura, affordabbli, cekkjatur). Although it is clear that the affixes are used productively in the creation of neologisms in these cases, they would not qualify as hybrid formations in many definitions, since the English bases are not native.

For the present investigation in Maltese, theses formations are nonetheless counted, as concerns Seifart's first criterion, since it is assumed that the term hybrid formation simply refers to cases where an affix is applied to a base that is not etymologically from the same source language as the affix and has likely been coined in the target language. Further complications surface when dealing with Maltese formations containing Italian/Sicilian bases which do not display the same base+suffix combination in the source language, such as in the case of Maltese reklutag $\dot{g}$ 'recruitment' vs Italian reclutamento 'recruitment'. Here, again, the affix -agg is used productively in a new formation, but not in the sense of Seifart's first criterion (ratio of complex loanwords to hybrid formations). These formations are not counted in my analysis of the Maltese affixes, although they also might be indicative of certain borrowing processes. Despite minor criticisms about the technical details of the calculation, Seifart's approach is a valuable quantitative method for distinguishing different borrowing routes based on empirical corpus data. In Table 9, Seifart's measures are calculated for the sample of three Italian derivational affixes in Maltese whose productivity ranks deviate from their Italian counterparts.

For the investigated affixes, Seifart's first criterion (Ratio of complex loanwords to hybrid formations) strongly suggests an indirect borrowing route. As discussed before, $\{-n z a\}$ does not produce any hybrid formation in Maltese, but also $\{$-tura $\}$ and $\{-a \dot{g} \dot{g}\}$ occur in only $5 \%$ and $3 \%$, respectively, of all hybrid formations. The proportion of complex loanwords with a corresponding simplex base varies from $20 \%$ for $\{-a \dot{g} \dot{g}\}$ to $30 \%$ for $\{-n z a\}$ and $37 \%$ for $\{-$ tura $\}$, scoring relatively low for an indirect 
borrowing scenario. The proportion of complex loanwords that are infrequent relative to their simplex bases is even lower in Maltese for all affixes and extremely low for $\{-a \dot{g} \dot{g}\}$ with only $6 \%$. Thus, Maltese exhibits diverging results regarding the most probable borrowing scenario for these affixes: extremely high proportion of complex loanwords in comparison with hybrid formations (criterion 1), low percentage of pairs of complex and simplex loanwords (criterion 2) and extremely low proportions of infrequent complex loanwords compared to their bases (criterion 3). This presents a case that is not present in Seifart's original taxonomy of case studies and might fill a gap in the typology of contact languages with direct and indirect borrowing scenarios as proposed by Seifart (2015:527). Given the known contact history of Maltese (long and intensive contact with Sicilian/Italian, high bilingualism), an indirect borrowing scenario seems to be the most likely route. Seifart (2015) also gives more weight to the first criterion, with respect to which, in my case study, all Maltese affixes score very high. Nonetheless, the low values for criterion 2 and 3 may point to a special situation in Maltese, where direct borrowing might have played a minor role at some point in contact with Sicilian/Italian.

The application of Seifart's criteria in conjunction with the comparison of productivity ranks using a modified Baayen's $P$ and the proposed Integration Factor pave the way for a more detailed discussion of the explanatory value of these measures and the general value of comparing productivity ranks as a tool in language contact studies.

\section{Productivity as an additional diagnostic for different borrowing scenarios}

As concerns the topic of this special issue of Morphology, MAT and PAT borrowing, morphological productivity measures of borrowed affixes are hard to categorize with respect to this dichotomy. Clearly, distributions and frequencies such as the productivity rankings discussed in this paper cannot be borrowed as patterns directly but are epiphenomenal to MAT borrowing. Productivity rankings of borrowed derivational affixes form a pattern (but not a directly borrowable PAT) that is established by the sum of MAT borrowings of the formations with the respective affixes. Nonetheless, the cross-linguistic comparison of productivity can shed light on cases of PAT borrowing or even detect deviating application patterns for certain formatives. The comparison of the productivity of Italian-origin affixes in Maltese with the productivity of the sources affixes in Italian can be used as an exploratory tool for identifying specific types of language contact scenarios. While it is a coarse measure not taking into account the actual capacity of creating neologisms or the applicability of formatives to 'native' bases (which the proposed Integration Factor can be used for), it can provide a general measure of how similar the application patterns of affixes in the source and recipient languages are. Strongly diverging productivity ranks would point to a more rapid or restricted contact scenario, while largely consistent productivity ranks would point to a more gradual and unrestricted contact scenario (as in the case of Maltese and Italian). Table 10 shows a tentative classification of three variables in language 
Table 10 Proposed correlation between productivity ranks of borrowed affixes and language contact scenarios

\begin{tabular}{lll}
\hline $\begin{array}{l}\text { Variables in language contact } \\
\begin{array}{l}\text { Intensity of contact } \\
\text { (Thomason 2001:60-66) }\end{array}\end{array}$ & $\begin{array}{l}\text { Predictive of less similar } \\
\text { productivity rankings }\end{array}$ & $\begin{array}{l}\text { Predictive of more similar } \\
\text { productivity rankings }\end{array}$ \\
$\begin{array}{l}\text { Available registers/repertoires in } \\
\text { contact (Matras 2009:43-44, 53) }\end{array}$ & Few & High \\
$\begin{array}{l}\text { Type of borrowing } \\
\text { route (Seifart 2015) }\end{array}$ & Direct borrowing & Many (all) \\
\hline
\end{tabular}

contact $^{11}$ and how they could influence the similarity/dissimilarity of productivity rankings of the contact languages.

The first very general variable "Intensity of contact" is further broken down by Thomason (2001:66) into three subvariables, viz. duration of the contact period, number of speakers of the two languages in contact, and socioeconomic dominance. The relevant influence on productivity rankings is straightforward: the longer and more intensive the contact with another numerically and socioeconomically superior group of speakers, the more opportunity (and pressure) for a speaker to fully acquire a morphological pattern through more and more exemplars of morphological rules (MAT borrowings). For Maltese, the long period of contact with Sicilian/Italian, roughly 1000 years from the Norman conquest of Sicily in 1025 until today (even if at low intensity for the last 100 years), clearly points to a high intensity for the first factor. Socioeconomically, the group of Sicilian and Tuscan speakers was always more powerful than the Maltese speaking population. Admittedly, the number of speakers of Italian and Sicilian in Malta itself was not always high, for example only 3000 foreigners lived in Malta in 1530 compared with 17,000 Maltese (Brincat 2011:148). However, with the advent of the Knights of St. John this changed at least locally in Valletta and the Harbour area, where the Italian speaking knights outnumbered the local population in the beginning of the sixteenth century (Brincat 2011:217). Intermarriages between the knights and the local population and also illegitimate children resulting from the contacts advanced the influence of Tuscan in Malta (Brincat 2011:220-224). Thus, also for the second and third subvariables (viz. number of speakers and socioeconomic dominance), the contact between speakers of Maltese and speakers of Sicilian/Italian can be classified as rather intensive even though Maltese speakers almost always outnumbered speakers of Italian and Sicilian in Malta.

The second variable, "Available registers/repertoires in contact", cannot be assessed as straightforwardly as the first one. Matras (2009:53) states that "since individual management of the multilingual repertoire is based on mapping repertoire

\footnotetext{
${ }^{11}$ A reviewer correctly points out that Frans van Coetsem's (1988) approach to language contact mechanisms, which distinguishes source-language agentivity (imposition) and recipient-language agentivity (borrowing), should be taken into account as a variable in further investigations of this kind. This presupposes a more detailed description of the exact degree and kind of bi- and multilingualism on Malta during the different stages of its contact with Sicilian/Italian/English. For a first insight how this approach can be applied to the Maltese case, please refer to Lucas and Čéplö (forthcoming).
} 
components to sets of activities, the stability of multilingualism depends on the stability of activity patterns. In some situations, participation in new activities will simply require the acquisition of a new language." Furthermore, cues such as "addressee, the setting, the context, and the topic of conversation" (Matras 2009:44) can shape the choice of language in multilingual settings. This also means that access to a wide range of communicative contexts, different addressees, and conversation topics can enhance the command of L2 structures in all their forms. The connection to productivity rankings lies precisely in this: the more registers a speaker uses (and is exposed to) and the more varied the communicative contexts a speaker participates in, the more likely application rules of affixes and the relative distributions of new types among each other (productivity) will be fully acquired. Since all the discussed cues (contexts, topics, addressees) are based on individual speakers and cannot be reconstructed for the contact of Maltese with Italian/Sicilian, the different used registers (high vs low) and possible specialist vocabulary are chosen, instead, as macro standins for the more fine-grained variables proposed by Matras (2009). The available or used registers differ for earlier Sicilian contact and later Tuscan Italian contact under the Knights of St. John. For Sicilian, Brincat (2011:103) notes that many technical and administrative terms were imported through chancery Sicilian (and also Latin) which were later also adopted in the spoken domain. On the other hand, also many terms from the lower register were imported from Sicilian. For contact with Sicilian, Brincat (2011:116) concludes that "the adoption of Romance words developed along two parallel lines: on the higher level by the absorption of learned words through the upper social channels, mainly in, or reinforced by, the written register, and on the lower social levels through oral contacts." For Tuscan Italian, introduced by the Knights of St. John, the situation is similarly varied. It was used very generally as "a tool for multinational communication" (Brincat 2011:202), although in the beginning especially many technical terms (especially concerning construction) seem to have been adopted by the Maltese (Brincat 2011:233-236). In summary, the amount of different registers and repertoires available to Maltese speakers during language contact with Sicilian and Italian can be classified as quite high: words from high and low registers were borrowed even if some domains such as law, administration, or construction techniques dominated at different points in time.

The third variable proposedly associated with converging or diverging productivity rankings is "Type of borrowing route". In contrast to the first two variables in Table 10, it does not represent a sociolinguistic variable but a structural property of the outcome of language contact. As demonstrated for Maltese in Sect. 5.3 (at least for three borrowed affixes) Seifart's (2015) measures at least tentatively point to an indirect borrowing scenario. The correlation of converging productivity rankings and indirect borrowing scenarios is evident from Seifart's measurements: the presence of simplex bases and complex (non-hybrid) formations presupposes a wider knowledge of possible types of a certain morphological process, whereas the absence of simplex bases for complex formations with borrowed affixes points to direct borrowing without extensive knowledge of the source language. The implication for productivity rankings of borrowed affixes is the following for direct borrowing: when affixes are borrowed without accompanying simplex bases and complex (non-hybrid) formations with very limited knowledge of the source language, the prediction is that 
productivity rankings of borrowed affixes in the recipient language will diverge quite strongly from those of the source language, because most of the simplex exemplars as domains for application are missing and complex (non-hybrid) formations as exemplars of the outcome of a morphological process are also missing. In the opposite case (i.e., indirect borrowing), as in the Maltese scenario, many exemplars of a morphological process are available for the speaker of the recipient language; therefore, convergent productivity rankings with the source language affixes are more likely to be expected as an outcome.

In sum, the contact scenario involving Maltese and Sicilian/Italian fulfills all traits from the rightmost column of Table 10 (high intensity, many/all linguistic registers/repertoires available, indirect borrowing of the compared affixes) predicting similar productivity rankings with the affixes in the source language (Italian). In the comparison of productivity rankings in Sect. 5.1 we saw that this prediction is partly borne out. The first four affixes align perfectly in rank, while the lower three affixes show some deviation in rank. However, perfect alignment of productivity rankings in two contact languages should be considered the extreme pole of this predictive classification of factors (the same is valid for totally diverging rankings). Furthermore, even if two languages exhibit perfect alignment of ranks at a certain point in time, this does not preclude any of the languages from undergoing separate and unrelated changes in the derivational system (and thus changes in individual productivity ranks) even after contact between the languages ceased or diminished. Extrapolating from a single contact scenario is not wise, so this predictive scale should be interpreted as a first step towards the application of the method proposed in the present paper. The proposed continuum of productivity rank similarity can easily apply to other contact scenarios, which makes it a reproducible and assessable heuristic tool. Other factors, such as for example, degree of bilingualism, language shift vs. maintenance, were not discussed here either. These can also contribute to achieving more fine-grained predictions in future applications of the proposed method.

\section{Conclusion}

This paper has shown that a triangulation of quantitative methods (Baayen's $P$ in combination with a variable corpus approach, the proposed Integration Factor, and Seifart's criteria for direct vs indirect borrowing) can provide insights into the borrowing of Sicilian/Italian derivational affixes and their integration into Maltese. The comparison of productivity ranks between borrowed derivational affixes in the recipient language Maltese and their sources in the source language Italian showed that the relative rankings are identical for the most frequent affixes and diverge slightly for infrequent affixes. While productivity rankings are not patterns (PAT) in the technical sense of Sakel, they nonetheless describe distributions of affix application created through matter borrowings (MAT). In the case of Maltese and Sicilian/Italian, a long and intensive contact history, the socioeconomic clout of the speakers of the source languages, varied available registers in contact, and the most likely indirect borrowing of the affixes led to mostly converging productivity rankings. In different language contact scenarios where contact intensity is low, only few restricted registers 
are transmitted, and direct borrowing occurs, the proposed model predicts diverging productivity between the recipient and the source language. While the comparison of productivity rankings can provide hints regarding possible contact scenarios, it has been shown that it is not a good measure for integration of borrowed affixes in present-day Maltese since hybrid formations with the Sicilian/Italian affixes do not cluster in the frequency class of hapax legomena. Instead a new proposed measure, the Integration Factor (IF), can provide a more meaningful measure of integration of borrowed affixes, since it directly computes the number of hybrid formations of an affix in relation to its total token count in a given corpus (IF $=\mathrm{HF} / \mathrm{N})$. Both the cross-linguistic application of productivity measures and the proposed Integration Factor should be valuable additions to the toolkit of morphologists and contact linguists alike.

$\begin{array}{ll}\text { Abbreviations } \\ \text { AGT } & \text { agent } \\ \text { COLL } & \text { collective } \\ \text { DEF } & \text { definite } \\ \text { F } & \text { feminine } \\ \text { IPFV } & \text { imperfective } \\ \text { M } & \text { masculine } \\ \text { NMLZ } & \text { nominalizer } \\ \text { PASS } & \text { passive } \\ \text { PFV } & \text { perfective } \\ \text { PL } & \text { plural } \\ \text { PROG } & \text { progressive } \\ \text { PTCP } & \text { participle } \\ \text { SG } & \text { singular }\end{array}$

Acknowledgements Open Access funding provided by Projekt DEAL. I thank the participants of the following conferences for their valuable input in the creation of this paper: Mediterranean Morphology Meeting 2015 in Haifa, Lingwistika Maltija 2017 in Bratislava, SLE 2017 in Zurich, Romanistisches Forschungskolloquium 2018 in Bremen. Albert Gatt and Ray Fabri deserve special mention for their support and advice during my 3-month stay in Malta 2016 where the bulk of the data for this paper was analyzed. As always, Thomas Stolz deserves special thanks for his support, attention to detail and constructive criticism concerning my work. In addition, I am grateful to two anonymous reviewers for their helpful questions and suggestions. Also, Francesco Gardani deserves praise for his efforts to make this manuscript better. On a more personal note, I want to thank my parents for taking care of my daughter Nola when I had to write for longer stretches. All errors and inconsistencies in this article are, of course, my sole responsibility.

Publisher's Note Springer Nature remains neutral with regard to jurisdictional claims in published maps and institutional affiliations.

Open Access This article is licensed under a Creative Commons Attribution 4.0 International License, which permits use, sharing, adaptation, distribution and reproduction in any medium or format, as long as you give appropriate credit to the original author(s) and the source, provide a link to the Creative Commons licence, and indicate if changes were made. The images or other third party material in this article are included in the article's Creative Commons licence, unless indicated otherwise in a credit line to the material. If material is not included in the article's Creative Commons licence and your intended use is not permitted by statutory regulation or exceeds the permitted use, you will need to obtain permission directly from the copyright holder. To view a copy of this licence, visit http://creativecommons.org/licenses/by/4.0/. 


\section{References}

Agius, D. (2012). Siculo Arabic. London: Routledge.

Aquilina, J. (1958). Maltese as a mixed language. Journal of Semitic Studies, 3(1), 58-79.

Baayen, R. H. (2009). Corpus linguistics in morphology: morphological productivity. In A. Lüdeling \& M. Kytö (Eds.), Corpus linguistics: An international handbook (pp. 899-919). Berlin: De Gruyter Mouton.

Bakker, P., \& Mous, M. (1994). Mixed languages: 15 case studies in language intertwining. Amsterdam: IFOTT.

Bonnici, L. (2009). Maltese English: History of use, structural variation and sociolinguistic status. In B. Comrie, R. Fabri, M. Mifsud, T. Stolz, M. Vanhove, \& E. Hume (Eds.), Introducing Maltese linguistics: selected papers from the 1st international conference on Maltese linguistics. Bremen, 18-20 October (pp. 393-414). Amsterdam: Benjamins. 2007.

Bonnici, L., Hilbert, M., \& Krug, M. (2012). Maltese English. In B. Kortmann \& K. Lunkenheimer (Eds.), The Mouton world atlas of variation in English (pp. 653-668). Berlin: De Gruyter Mouton.

Borg, A., \& Azzopardi-Alexander, M. (1997). Maltese. London: Routledge.

Bovingdon, R., \& Dalli, A. (2006). Statistical analysis of the source origin of Maltese. In A. Wilson, D. Archer, \& P. Rayson (Eds.), Corpus linguistics around the world (pp. 63-76). Brill.

Brincat, J. (2011). Maltese and other languages: A linguistic history of Malta. Sta Venera. Malta: Midsea Books.

Brincat, J., \& Mifsud, M. (2015). Maltese. In P. O. Müller, I. Ohnheiser, S. Olsen, \& F. Rainer (Eds.), Word-formation: An international handbook of the languages of Europe (vol. 5), Berlin: De Gruyter Mouton.

Cohen, D. (1965). A propos de l'analyse lexicostatistique des langues sémitiques. Comptes rendus du groupe linguistique d'études chamito-sémitiques, $X$.

Comrie, B., \& Spagnol, M. (2016). Maltese loanword typology. In G. Puech \& B. Saade (Eds.), Shifts and patterns in Maltese (pp. 315-329). Berlin: De Gruyter Mouton.

Drewes, A. J. (1994). Borrowing in Maltese. In P. Bakker \& M. Mous (Eds.), Mixed languages: 15 case studies in language intertwining (pp. 83-111). Amsterdam: IFOTT.

Evert, S., \& Baroni, M. (2007). zipfR: Word frequency distributions in R. In Proceedings of the 45th annual meeting of the ACL on interactive poster and demonstration sessions (pp. 29-32). Stroudsburg: Association for Computational Linguistics.

Fenech, E. (1978). Contemporary journalistic Maltese: An analytical and comparative study. Leiden: Brill.

Gaeta, L. (2004). I suffissi -tura e -aggio. In M. Grossmann \& F. Rainer (Eds.), La formazione delle parole in italiano (pp. 334-338). Tübingen: Max Niemeyer.

Gaeta, L., \& Ricca, D. (2006). Productivity in Italian word formation: A variable-corpus approach. Linguistics, 44(1), 57-89.

Gardani, F. (2008). Borrowing of inflectional morphemes in language contact. Frankfurt: Peter Lang.

Gardani, F. (2012). Plural across inflection and derivation, fusion and agglutination. In L. Johanson \& M. Robbeets (Eds.), Copies versus cognates in bound morphology (pp. 71-97). Leiden \& Boston: Brill.

Gardani, F. (2018). On morphological borrowing. Language and Linguistics Compass, 12(10), 1-17.

Gardani, F. (2020). Morphology and contact-induced language change. In A. Grant (Ed.), The Oxford handbook of language contact (pp. 96-122). Oxford: Oxford University Press.

Gardani, F., Arkadiev, P., \& Amiridze, N. (2015). Borrowed morphology: An overview. In F. Gardani, P. Arkadiev, \& N. Amiridze (Eds.), Borrowed morphology (pp. 1-23). Berlin, Boston \& Munich: De Gruyter Mouton.

Gatt, A., \& Céplö, S. (2013). Digital corpora and other electronic resources for Maltese. Presented at the Corpus linguistics 2013, Lancaster University, UK.

Gatt, A., \& Fabri, R. (2018). Borrowed affixes and morphological productivity: a case study of two Maltese nominalisations. In P. Paggio \& A. Gatt (Eds.), The languages of Malta (pp. 144-170). Berlin: Language Science Press.

Haspelmath, M., \& Tadmor, U. (Eds.) (2009). Loanwords in the world's languages: A comparative handbook. Berlin: De Gruyter Mouton.

Hay, J. (2001). Lexical frequency in morphology: Is everything relative? Linguistics, 39(6), 1041-1070.

Lucas, C., \& Čéplö, S. (2020). Maltese. In C. Lucas \& S. Manfredi (Eds.), Arabic and contact-induced change (pp. 265-302). Berlin: Language Science Press.

Majtényi, M. (2012). The productivity of the prefix über- in English and Hungarian: A cross-linguistic, corpus-based study. Argumentum, 8, 244-261. 
Matras, Y. (2009). Language contact. Cambridge: Cambridge University Press.

Mifsud, M. (1995). Loan verbs in Maltese: A descriptive and comparative study. Leiden: Brill.

Papoutsis, T. (2014). Measuring the productivity of noun-deriving suffixes across languages: Greek-tita vs. English-ness. In Major trends in theoretical and applied linguistics 1: selected papers from the 20th ISTAL, $1,421$.

Saade, B. (2016). Adverbial derivation in Maltese and Italian: A starting point for studies in cross-linguistic productivity. STUF - Language Typology and Universals, 69(4).

Saade, B. (2019). Assessing productivity in contact: Italian derivation in Maltese. Linguistics, 57(1), 5986.

Sakel, J. (2007). Types of loan: Matter and pattern. In Y. Matras \& J. Sakel (Eds.), Grammatical borrowing in cross-linguistic perspective (pp. 15-29). Berlin: De Gruyter Mouton.

Seifart, F. (2015). Direct and indirect affix borrowing. Language, 91(3), 511-532.

Spagnol, M. (2011). A tale of two morphologies. Verb structure and argument alternations in Maltese $\mathrm{Ph} . D$. Universität Konstanz.

Stolz, T. (2003). Not quite the right mixture: Chamorro and Malti as candidates for the status of mixed language. In Y. Matras \& P. Bakker (Eds.), The mixed language debate: Theoretical and empirical advances (pp. 271-315). Berlin: De Gruyter Mouton.

Thomason, S. G. (2001). Language contact. Edinburgh: Edinburgh University Press.

Tosco, M. (1993). Morfologia Italiana in Maltese. In R. Contini, F. Pennacchietti, \& M. Tosco (Eds.), Semitica. Serta philologica constantino tsereteli dicata (pp. 319-331). Torino: Silvio Zamorani.

Van Coetsem, F. (1988). Loan phonology and the two transfer types in language contact. Dordrecht: Foris.

Vanhove, M. (1994). La langue maltaise: Un carrefour linguistique. Revue du Monde Musulman et de la Méditerranée, 71(1), 167-183.

Vanhove, M. (2001). Contacts de langues et complexification des systèmes: le cas du maltais. Faits de Langues. Langues de diaspora. Langues en contact, 18, 65-74.

Versteegh, K. (2017). The myth of the mixed languages. In B. Saade \& M. Tosco (Eds.), Advances in Maltese linguistics. Berlin: De Gruyter Mouton. 